The Committee recommended that specialists in linguistics and ethnology should always be associated with national procedure for determining the orthography of place names on maps, and, more particularly, that these disciplines should be represented on any national or territorial toponymy committees.

Arrangements are now being made for a CCTA/CIE Symposium on Child Welfare in West Africa in February 1959. It is hoped to hold the next meeting of the Committee in Lisbon early in 1959 .

\title{
International Institute of Differing Civilizations
}

THe International Institute of Differing Civilizations will hold its 3 rst session in Brussels from 17 to 20 September 1958 , under the Presidency of M. Henri Depage. The subject discussed will be "The Role of Women in the Development of Tropical and Sub-Tropical Countries '. The subject will be examined in its legal, social and cultural, economic, and political aspects, each of which will be discussed in a general report. Some twenty special reports, dealing with the position in particular territories or regions, will be circulated beforehand so that participants may have the opportunity to study them closely in advance. After the opening session, discussion will begin immediately on the basis of questions at the end of their papers presented by the writers of the general reports. At the close of the debates conclusions will be adopted which will form a synthesis of the views put forward and will bring out their main trends. All the discussions will be carried out at plenary meetings. An editorial board consisting of the writers of the general reports will draft the conclusions.

\section{International Journal of Health Education}

THE first number of the official quarterly journal of the International Union for Health Education of the Public appeared in January. It contains a short account of the first African Seminar on Health Education of the Public which was held in Dakar from 25 to 30 March 1957, under the auspices of WHO in collaboration with the French Government. Dr. Louis Sanner, Director General of Public Health in French West Africa, also comments on this seminar in an article 'Striding ahead in Africa'.

\section{Ford Foundation-African Studies Fellowship Program}

THE Foundation has awarded the following grants for field research in $2958-9$ :

Norman R. Bennett (Boston): Islamic penetration of East Africa in the late nineteenth and early twentieth centuries (England, Zanzibar, and East African coastal areas).

Philip D. Curtin (Wisconsin): ' Native policy' in British West Africa during the nineteenth century (London, Sierra Leone, Ghana, and Nigeria).

Nicholas M. England (Harvard): Bushmen cultures in the Kalahari Desert, Southwest Africa, Bechuanaland, and Union of South Africa.

William H. Friedland (Berkeley, California): Process of industrialization and trade union development in Northern Rhodesia (Boston, England, and Northern Rhodesia).

Peter $R$. Gould (Northwestern): Transportation as a factor in the economic development of Ghana (Ghana).

John $R$. Howard (Northwestern): Personality variation in an Ibo village (Nigeria).

Gail M. Kelly (Chicago): An African dialect, and the effect of Western cultural traditions on Ghana.

Herbert S. Lewis (Columbia): Ethnographic study of the native kingdoms in southwest Ethiopia. 